\title{
Colonization of the world economy in the light of Testaments and the ideology of Muhammad (P.B.U.H)
}

"Muhammad Mashhood Ahmed

\section{ABSTRACT:}

The purpose of this treatise is the study of globalization in pertinence with trade and Commerce, its roots and linkage with different countries in the modern age, and the critical observations, assessments and analysis made on it, in the light of testaments and the ideology of Holy Prophet Muhammad (Peace be upon him), relevant philosophies, moreover, this write up meant to bring into in the lime light and discussions how the thought and approach of the societies and the communities that had religious-centric approach for seeking solutions to their social \& economical problems, was completely altered or at least impaired to a substantial degree. Modernization transformed the whole world, meanings of distances and relations were changed, and lifestyles of common peoples were given new shapes, business or working timings, as well as currencies were given totally different outfits, priorities and preferences got new specifications, and dimensions, subsequently new codes of customs and behaviors were devised. In the wake of modernization world witnessed a rampant revolution. The shift in priorities and preferences from religiouscentric to materialism, as well as acquisitiveness affected the overall moral, ethical and principled values, resultantly, inter-human relations and the social world was dressed with new kind of attires. This paper will be an attempt for helping us reaching and comprehending the vision and mindset, instrumental in selling the "slogan of globalization" and its impacts, cap-a-pie, on the society around the world in economic and religious respects before and after its application.

Keywords: Globalization, Testaments, religious-centric approach, economy.

\section{Introduction:}

Religion is any cultural system of designated behaviors and practices, world views, texts, sanctified places, ethics, or organizations that relate humanity to the supernatural or transcendental. Religions relate humanity to what anthropologist Clifford Geertz has referred to as a cosmic "order of existence"1. It is very much built in in our minds that all the religions are meant to offer a specific band of rules for its followers, in order to achieve eternal success, as well as inter-human relations, on individuals as well as communal basis ${ }^{2}$. In other words we can say religions provide mode de operandi to the ones who

"Ph.D Research Scholar, Department of Commerce, University of Karachi.

Email: mashhood_87@hotmail.com 
stay in this mundane world. It is obvious from the above observations that the fundamental basis of all the religions is the welfare of masses or common peoples and Islam too is no exception. The comparative study of all the religions can easily help us reaching the conclusion that they are meant to guide humans to a comfortable and peaceful living. For example, if Islam binds me to tell truth all the ties, then at same time, it is forbidding other to tell me untruth, if this policy is maintained, seventy to eighty percent of the disputes will cease to exist. In a nutshell, all the sacred texts forwarded by the different religions underline overall betterment of peoples and societies, rather than undermining humanity.

Prior to the modern times and specifically, before the industrial revolution (that came into its final shape in the last part of the eighteen century), all the societies were formed on the basis of religious backgrounds, other factors that had their roles in collecting humans for the reasons for socializing them were their customs, cultures and lifestyles or ethnologies, similar kinds of examples can be found in the world of current time ${ }^{3}$. Those societies were rich considering cultural and social backgrounds, they never feel alone even in the time isolation, and they had many reasons to hold them together. Moreover, they were enjoying blessings of piousness as well. In the process of civilization, refinement and modernization, world ushered into the state-of-the-art today which is described as sophistication, however, this idea was voiced for the first time in the history this planet with the following words:

"Today, after more than a century of electric technology, we have extended our central nervous system itself in a global embrace, abolishing both space and time as far as our planet is concerned".Marshall McLuhan, Understanding Media, 1964.

In wake of the modernization process, this "satellite town of the solar system" is completely altered, however, the thing that didn't change and will never change is "human values" which is governed and regulated by religions, still a silent majority of the peoples worldwide, is conservative and believes in religions and rationalism. It is worth speaking the fact that the masses throughout the world, still expect their political authorities to retune their direction, orchestrate themselves on true guidelines provided by believes, in handling all the matters they need to negotiate with (Seharvi, July 2010). Due to this reason, few may consider it as a mascot, serving bonanza to the cause, however may feel otherwise, on the other hand, majority, despite considering as boon but not at least in 360 degree directions, some might contemplate it in complete welfare of the globe, provided, if it were to offer its productivity to 
the entire humanity, irrespective of races, languages nations and religious discriminations ${ }^{4}$.

It is worth mentioning that the critical lines that is drawn between evil and bad of its goodness or badness depends on its effects that how far it remains effective for the individuals of the society. In fact, it carried into effect with effect from last two decades when a rapid change incurred by shaping the shape of trade and commerce and financial institutions through the use of modern technology and modern innovations such as internet and overseas shipping around the global village. This shift in the basic trade system and ushering into the modern electronic age provided new basis for starting great debates and discussions amongst the economists and the subject experts of the relevant spheres. In the following lines incorporate some notable reflections from the recognized scholars. One of well-known Indian economist "A. Amartya Sen" who was awarded with Nobel Prize in his field on "account of welfare economics in 1998", He expressed his thought with the following words ${ }^{5}$;

"Globalization has enriched the world scientifically and culturally, and benefited many people economically as well"

On the other hand, Prof. Joseph Stieglitz, an American Nobel Prize winning economist in the same field stance the process of globalization as "disparity in the world rather than reducing it".

\section{Overseas Investments:}

Whereas, the political authorities of different geographical and administrative blocks have been treating and governing their realm by formulating, legislating and implementing the laws, that suits them the most. In other words, the world that was stretched to total area of 510.072 million sq km (196.940 million sq $\mathrm{mi})^{6}$, was literally reduced into a village like town, and is being run according to the desires and wishes of those who had never contributed anything for the wellbeing of the communities, on the other hand however, they did not spare anything they could do, to satiate their mal objectives and desires, they know how to get their breads buttered. The term globalization encompasses a whole world, and wide spectrum range of applications and considerations; however this write up meant to focus only the subject matter. However, it will be attempted to incorporate few human achievements that played key roles in reducing humanity into a single urbanization. In actual fact, discovery of electromagnetic waves in early nineteenth century by Maxwell, development of radio telegraphy (in 1893) by Marconi, as well as radio telephony in 1906 by Reginald Fessenden, discovery of x-ray also, moreover, first ever transatlantic 
telephone call in 1908 December 3, 1917, expedition by the wright brothers, development of first ever antibiotic in 1930, televising of Munich Olympics in 1932, queen Elizabeth's marriage ceremony, and the post-world war II era that marked the beginning of space age, did decisive job in enveloping earth and turning it into one residential unit ${ }^{7}$.

In under developed countries, foreign investment is never meet with highest level of acceptance amongst the common people, understandably, foreign investment affects a nation in three sixty degree directions, it influences the basic ethnology of the host nation, however, which factor gets most affected due to it, is trade and industry. It won't be irrelevant to mention here that the foreign investors, to serve their specific designs and interests, completely alter way of living or lifestyles of the masses according to their own interests. ${ }^{8}$

On the other hand, it is also poses a threat of unemployment to the people of investors countries, due to possibility of shifting their workstations to the countries or locations where the cost of labour could be cheaper. In the eighth and ninth decades of the preceding century, world witnessed shifting of workstations from Japan to Malaysia, Indonesia, Thailand, Hong Kong, and China, where Japanese could find cheaper workstations and laborers. In the modern times, investments from all over the globe are amassing in China. And resultantly, we are seeing an industry galore in China which is now emerging as new super power of the world ${ }^{9}$. On the other hand, exceeding production of commodities documented a severe health issues for their society.

\section{Historical Background of Globalization:}

Jeffrey Gale Williamson, a Professor of Economics, researcher and writer, who authored many books including "Globalization and the poor" observes the emerging process of globalization was witnessed for the first time $19^{\text {th }}$ century, and according to him, it did happen due to a great fall experienced in the prices of transport cost which affected prices of merchandises as a whole, in the entire continents of Europe and Asia.

On the other hand some other economists believed that its process was started in 1492 with the discovery of the USA. The thought that provided impetus to reaching this conclusion was discovery of huge silver reserves in that part of the globe ${ }^{10}$. Without any kind of doubts it was that unearthing that immensely affected the European states as their currencies had a strong link with the value of silver at that age. Adam Smith argued that it diverted the economy on a new trend which is said to be process of globalization. It also manifested, that a country underwent economic instability or suffers due to unpredictability of market prices due to monetary change in another country or in other words, the 
economic effects were recorded in different states because of the discovery of mines containing huge silver reserves in other country. Another case can also be refer here, and it happened in the sixteenth century, and this time, both gold and silver underwent devaluation in the European states, and the reason was plentiful supply of precious metals to the market, which was produced by using cheap labor that is also linked with the beginning of globalization. Another economist Andre Gunder Frank, who belonged to Germany, linked the process of globalization with the growth of trade and market amalgamation amid Sumer and Indus civilization during 3000 BC. According to him, a trade link between Europe and China which was established and developed during the Hellenistic age, moreover, it were its effect that proved a stepping stone in the development of market globally ${ }^{11}$.

It is worth mentioning that the process of globalization is directly associated with the pace of integration of markets of different countries, it might either by force or by one sided economical interest, however, it does happen with mutual consent of the political and administrative authorities of the relevant countries. This is why, the undisputed consensus is found among the economists of the world in pertinence with the process of globalization that it increases in the volume of trade of the states but unfortunately no one give due considerations to it with respect to demand and supply, the market requirement, public interests, and their buying power and affordability. However, it will not be inappropriate to incorporate here that variations in the volume of trade can also be resulted due to some other causes like increase in population, change, modification, innovations and advancement in technologies, induction of new equipment, skills and expertise, mass movement of peoples due to some natural disasters besides capital growth etc.

History of this planet enough support to this idea that all the modifications resulted on account of globalization during the age, happened as a consequence due to unethical and uncivilized attitude of the powerful countries. No respite for the poor nations and countries, powerful economies continues to feast on the weaker nations, maintaining their stronghold on them, monopolizing maximum possible fields as well as natural resources of this globe by and large. Subsequently, opportunities and possibilities for indigenous investments and financing suffered gravely. In view of the facts already incorporated above, it will not be illogical or irrational to conclude that the notion of globalization is not the best of the ideas, and in actual fact, it is much distant phenomenon from the realistic and rational world and are not enjoying conventional values of this part of the universe ${ }^{12}$, and its credential continues to remain questionable and 
under stigmas.

\section{A Sacred Approach to Globalization:}

It would not be out of place to incorporate here that the ones that had the reins and harnesses of the people on account of the religious dominions, never pay heed to the problems of the common peoples in specific context with economic issues, across the world, yet is also feeling that were equipped with true capacity necessary to dealing with. Consequently, the social and political lives of the people have no connection with their holy places including mosque, church, mandir etc (Wilson 2010). Resultantly, we see bloodbaths all around us that is best expressed by Allama Iqbal with the following way;

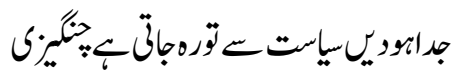

In other words, we can say that the phenomena and factors could have control peoples to remove materialisms from their lives were actually sent to coldrooms. They were only made limited to cherishing and celebrations of specific days and occasions and nothing else. Indeed, different religious groups are working with the spiritual backgrounds, all around the globe.For instance, only, in the continent of Asia, thousands of organizations are registered on account of sectarian basis, working well in their domains but they have no effective roles in economy and addressing its problems, however, they are very much punctual in celebrations and festivity of specific days and occasions throughout year (Wilson, E.K. 2010). Most famous common matters of them are Holi, Easter, are as Eid Milad un Nabi, Moharram and Urses etc. Factually, their headships hardly possess any knowledge regarding subject matter of this paper.

\section{Christianity Discourse:}

Amy Reynolds, the Dean of the College of Communication and Information (CCI) at Kent State University, underlined the viewpoints of different religious authorities' belonged to different churches all over the world, including the USA and Canada, about globalization. Reynolds asserted that they all including their scholars, supported the policy of globalization with respect to free trade despite the fact that they underlined the economic issues with respect to standards of life and negated all those who were in opposition to this thought in the current age ${ }^{13}$. Reynolds termed religion as effective voice, highlighted the importance of religion in pertinence with the matter as incorporated above. Initially, she focused on the gridlines through which social and political ideas and values weaves through their threads, and tried to explain why religion was especially important voice to be considered in discourse about the trade which shaped the structure of current markets.

Then, through three well researched case studies, the author reached the concl- 
cusion that the way in which religious communities asked the people to engage in new approaches to thinking about the market, how institutional factors influenced the shaping, and how the communities have worked to create alternative networks and policies governing economic and social life.

\section{Jewish Discourse:}

History contains rich material to sustenance this idea that The Jews cannot be separated from the process of globalization. Moreover their association is visible from all the angles of considerations and criticisms. On the other hand however, it is too an undeniable truth that they suffered gravely in this process, in actual fact their community was brutalized, Chancellor Hitler, a well-known German politician and autocrat, epitomized era that is usually regarded as "Nazi Germany", in a quest to take hold of a number of European sovereign states and subjugating them in their Nazi rule, (in the process of globalization), and consequently, the world community witnessed that about six million peoples belonged to Jewish community were brutally slaughtered (in the history, the tragedy is identified as Holocaust $)^{14}$. The miseries of the Jews were not limited to the bloodbaths set by Nazis and Adolf Hitler, in fact their grievances continued, and on the other occasion, it was Joseph Stalin was the key figure. They were massacred under the auspices and joint venture of communist and Christian ideologies ${ }^{15}$.

Coming back to the theme of this write up, "globalization", in actual fact it was against the preaching of Jewish's religion, therefore they were never in support of that indoctrinations, consequently, they were victimized through the hands of people who were opposed. The mindset of the Jewish community had a strong belief concerning such practices, they were aware that their traditions and religious rituals would be sacrificed. Further to that effect, the modern day globalizing of USA, European Union and United Nations is the fruit of one rule, globally followed by every individual and every state with the common interest, focusing more towards comforts of life, securing all grievances mentioned in the Holy Scriptures and securing and maintaining dominating position across the globe. It said to be spirituality that Jewish globalization as they have strong believe on their religions and said to be strong followers with their culture, religion and maintaining it (Niall, 2008). Further, another well-known historian named Simon Dunbnow who treated this community like "am Olam" who believed that the entire world is our home and we are citizen of this world ${ }^{16}$

\section{Hindu Discourse:}

Mainly Hinduism belongs to the land of India which is preferred politically, Socially and individually at large over there. They claim over $15 \%$ of world 
population to their followers live in across the world. Over 850 languages and dialects are spoken it mean hundreds of different cultures and different ethnology and beliefs are existed and at the same time securing their liberty in Indian Territory. It enhances the beauty of the soil and fills multiple colors in their lives and distinguishes them with other societies which can be viewed and realized by naked eyes. The development of globalization play a great role to connect each other and increase similarities among different cultures and modernize different ethnology therefore it was a need to disclose above precisely. In fact, it also affected Hindu religion, frankly speaking, a group of holding more conservative thought about religion or conventional followers moved towards isolation while rest of became more liberal and established their social connections with the followers of other religions and promoted similarities that may be seen in the land of India (Beyer, 1994: 86ff). However, it is not good in accordance with Hindu religion's preaching which promotes simple life for securing brotherhood globally. It is commonly believed among the Hindu societies that it affected their civilization by removing respect of elders, promote materialism, individualism, excessive consumerism, lust for money and abandonment of moral values among the public. They also believe that break up of joint family system is also caused of it. In addition, that's the reason, Mr. Obama, Ex: President of United State of America who strongly felt and realized the need of strong family system for healthy society for his country which ensures the importance of family system which has been unforeseen with the development of globalization along with independency of individuals across the world.

\section{Mulsim Discourse:}

The Holy Prophet Muhammad (P.B.U.H) was sent as the last messenger who introduced a complete code of life in twenty three years of his prophecy. The blessing of his preaching has been acclaimed for the entire humanity and will continue to serve Pharos till the doomsday. It almost secured from all kind of traditional, conventional and situational changes which come into being with the passage of time across the world. Moreover, it also provides complete solutions to the global problems. After the conquest of Makkah in $630 \mathrm{AD}$, he gave a Khutbah regarding globalization on account of equal rights of economy at the time of performing Hajj which is generally regarded as Khutba e Hujja Tul $V_{i d a}{ }^{17}$. Few salient characteristic of his speech are as under;

On that auspicious occasion, certain divide and separation lines were drawn between rights and wrongs, truths and untruths, humanity given the respect it truly deserved, it was elevated to the altitudes it never reached before, Rahmat 
ul-Lil-Alameen $(S A W)$, on the occasion of Haj-e-Mubarak, presented Khutbah Hajjatul Wida (the farewell sermon). It portrays basic and elemental principles of Islam, simple methodology for living, complete guide and a perfect code of life. It is the ever best sermon in the history of this planet. It is unanimously accepted as the Charter of Human Rights. On this occasion killing and taking one's property was made Haraam. He further stated that a Muslim is brother of another Muslim and thus all are brothers among themselves. The rights of women were met with acknowledgement; in actuality women had no right to live a respectful life like men had before dawn of Islam. Rahmatul-Lil-Alameen $(S A W)$, on that day pronounced restoration of respect and disgnity for that part of the society, Rahmatul-Lil-Alameen $(S A W)$ maintained: "O People, it is correct that you have certain rights with regard to your women, however they also have rights over men. Do them the best of treatment and have kindness for them, as they were made your associates and devoted partners."

In total contradiction to rest of the religions, Islam promises a system that offers equal opportunities for every individual irrespective of class, race and language diversifications, however, it is need to be established that equality in economic growth and prosperity can't be promised amongst the peoples, because everyone works and functions according to his or her abilities, capacities, physical and financial limitations, social and environmental constraints, as well as ranges of choices and opportunities, play instrumental and decisive role in deciding destiny and fates and consequential categorizing classifying social levels amongst individuals ${ }^{18}$.

Quran in this context states:

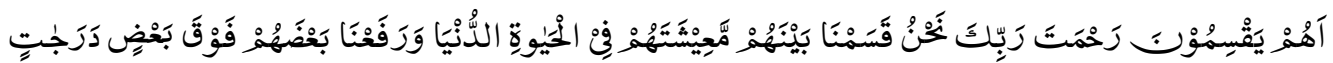

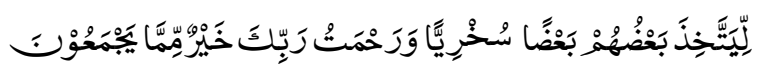

Is it they who allocate the mercy of your Lord? It is we who have allocated their livelihood in this life, and we elevated some of them in rank above others, that some of them would take others in service. But your Lord's mercy is better than what they amass. (Sura Zukhruf, Verse 32)

Before coming to explain the matter here, I take opportunity quote a line from the bible that says that "Money is the root of all evil". On the other hand George Bernard Shaw asserts as, "The lack of money is the root of all evil". Definitely, equality in economy and its growth can't be guaranteed however, Islam (that is merely not an economic system or religion, it's a complete DEEN) doesn't support imbalanced economy, unfair distribution of wealth, inadequate and unreasonable money minting opportunities and resources 
amongst different class of peoples and communities. On the other hand, it doesn't like broadening of gap between the poor and the rich, when this gap widens the poor goes worst to worsen and rich goes caresses new heights every day. It is a system of injustice, malice and brutality; it breeds hatred and loathing, and give birth to a system of living that can't survive and bound to be perished sooner. It further clarified by the following Hadees which put forward another step towards boundary less world.

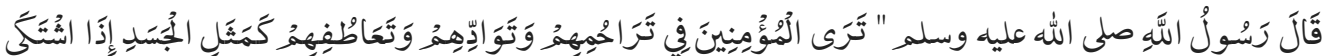

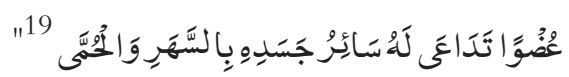

Allah's Apostle said, "You see the believers as regards their being merciful among themselves and showing love among themselves and being kind, resembling one body, so that, if any part of the body is not well then the whole body shares the sleeplessness (insomnia) and fever with it.

\section{Conclusion:}

It is significant enough to be noted that concept of globalization can neither be linked with the period of $18^{\text {th }}$ century when only luxury goods were traded amongst different countries meant for satiating needs of upper class, nor it can be related with the $19^{\text {th }}$ century when common goods including textile articles as well as wheat were integrated in the large scale foreign trade. In total contravention to the phenomenon, it cannot also be related with the situation of the modern times, when we are seeing the world population as single urbanization, and the world itself has been reduced into a small village. And it is due to the fact that it is almost a tailor made situation for the super powers and influential nations and countries for minting money, whilst raising slogans for free trades and borderless world. The reader has every right to feel otherwise.

Likewise, the same kind of situation is developing when an infrastructure is being weaved in the entire territory of Pakistan, in pertinence with CPEC (the China Pakistan Economic Corridor); however the terrains that are more focused in this connection are in Baluchistan. Keeping in view the potentials of this project, and its capabilities of serving a game changer in the regional politics as well as in the economic activities, CPEC is not getting the highest level of acceptance among the rivals and neighboring countries. Resultantly, nowadays, the country is facing serious kind of threats to its sovereignty and menaces related to internal insurgencies (though, they are controlled by the foreign powers).

In a nutshell, the study of this write up took the writer to the conclusion that the quest (as referred above), to subjugate weaker economies, and prey on the flesh 
and blood of the less-powered countries the powerful countries continues with their wills, which is strictly against the preaching of all the known religions (the most prominent of them are Hinduism, Christianity, Jewish and in Islam) of the world. Therefore, it is the reason that provided impetus to separating religions and religious practices from the administrative, political and governmental methodologies all over the world. now ultimately, we are witnessing hidden faces trying hoisting the flags mentioned slogans for secularism.

According to our research we further found that the concept of globalization only recommends and warrants a world without borders for influencing the international trade and markets, strictly, serving interest and designs only of the powerful nations. It capacitates them to intervening and influencing markets of other countries, affecting and tuning immigration and labor policies in order to creating attractive pools in their countries for laborers of other nations, so they could acquire cheaper laborer's. As a matter of fact, it's too a reality that in contrast to the believers, the world of nonbelievers or pagan world, situation is more painful for the foreign laborers, for example, in case of Chinese States or Indochinese countries, we see no religion dictation (drawing line between Halal and Haram) on their foods, conversely entire European and other states of the world where reached the preaching of religions they are very conscious about their meal.

Briefly, the finding of this research paper also supported by Mr. John Perkins who pulled into discussion a lot of things in his book titled "Confession of an Economic Hit Man" related with the practices of globalization promoted by the political authorities of the world, he asserts that "it is only their monetary interest which is serving an impetus behind promotion of globalization. In addition, no alliance of countries or a country itself can ever achieve a healthy and prosperous living in the long run by exploiting others, or practicing as "beasts of prey" and at the end it is bound to face destruction, devastation and failure.

\section{Bibliography:}

${ }^{1}$ Gwynne, P. (2009). World Religions in Practice: A comparative Introduction (First ed.). Oxford, United Kingdom: Blackwell Publishing Ltd.

${ }^{2}$ Beyers, J. (2015). Religion as political instrument: The case of Japan and South Africa. Journal for the study of Religion, 28(1).

${ }^{3}$ Seharvi, H. R. (July, 2010). Islam Ka Iqtesadi Nizam. Karachi: Shaikh ul Hind Academy. 
${ }^{4}$ Mervat F. Hatem; In the Eye of the Storm: Islamic Societies and Muslim Women in Globalization Discourses. Comparative Studies of South Asia, Africa and the Middle East 1 May 2006; 26 (1): 22-35.

${ }_{5}^{5}$ Sen, A. (1999). Development as Freedom (First ed.). Oxford University Press.

${ }^{6}$ Barney, O. G. (1981). The Global 2000 Report to the President of the U.S Entering the 21st Century (The Technical Report) (Vol. II). United States of America:

Pergamon Press.

${ }^{7}$ Windelspecht, M. (2003). Ground Breaking Scientific Experiments, Inventions and Discoveries of the 19th centuries. London, United Kingdom: Greenwood Press.

${ }^{8}$ Landell-Mills, J. (Ed.). (January 1988). Foreign Private Investment in Developing Countries (A study by the Research Department of hte International Monetary Fund). Washington, D.C.: External Relations Department, Attention Publications, International Monetary Fund, Washington D.C.

${ }^{9}$ Rosenau, J. N., Held, D., McGrew, A., Goldblatt, D., \& Perraton, J. (1999). Global Transformations (Politics, Economics and Cultures). Stanford, California: Stanford Univeristy Press.

${ }^{10}$ Ritzer, G. (2016). The Blackwell companion to globalization. Malden: Wiley Blackwell.

${ }^{11}$ Frank, A. G. (2011). Andre Gunder Frank and Global Developement. (P. Manning, \& B. K. Gills, Eds.) Abingdon, Oxon, England: Routledge Taylor \& Francis Group. ${ }^{12}$ Wilson, E. K. (2010). Beyond Dualism: Expanded Understandings of Religion and Global Justice. Interanational Studies Quarterly , 54 (3), 733-754.

${ }^{13}$ Reynolds, A. (2014). Free Trade and Faithful Globalization. Cambridge Univeristy Press.

${ }^{14}$ Ferguson, N. (2008). The Ascent of Money. The Penguin Press HC.

${ }^{15}$ The Holocaust Encyclopedia.

${ }^{16}$ Jewish Encyclopedia.

${ }^{17}$ Azad, A. A.-K. (1970). Rasool-e-Rehmat. (G. R. Maher, Ed.) Lahore, Punjab, Pakistan: Shaikh Gulam Ali Sons, .

${ }^{18}$ Modudi, M. S. (2013). Ma'ashiat-e-Islam. Lahore: Islamic Publications Ltd.

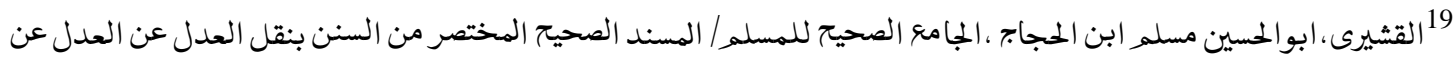

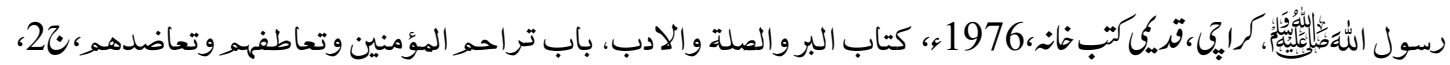

